\title{
Seasonal and Spatial Dynamics of Physico-Chemical Characteristics as a Factor for Water Quality Deterioration in Legedadi Reservoir, Ethiopia
}

\section{Adane Sirage $\mathrm{Ali}^{1 *}$ and Demeke Kifle Tsega ${ }^{2}$}

${ }^{1}$ Department of Environmental Science, Kotebe Metropolitan University, Addis Ababa, Ethiopia

${ }^{2}$ Department of Biology, Addis Ababa University, Addis Ababa, Ethiopia

\begin{abstract}
The water quality of Legedadi Reservoir, which provides more than seventy five percent of the water supplies to Addis Ababa City, is deteriorating from time and time. The reservoir has suffered water quality problems for several decades due to unacceptable changes in the odor, color and other parameters. In this study the seasonal and spatial dynamics of physico-chemical parameters of Legedadi Reservoir were investigated at monthly intervals. The study was conducted from November to August at three study Sites (represented as Sites 1,2 and 3) in the reservoir. All physicochemical parameters were measured using standard techniques in Addis Ababa Water and Sewerage Authority, Central Laboratory. The reservoir is characterized by unusually high turbidity throughout the study period (with most values $>400$ NTU) mainly due to sediment influx during run off and resuspension of sediment. Secchi depth (transparency) of the reservoir was extremely shallow and (always $<10 \mathrm{~cm}$ ) and showed both seasonal and spatial variations $(7.6 \pm 0.6,8.3$ \pm 0.9 and $8.1 \pm 0.6 \mathrm{~cm}$ at Sites 1,2 and 3 respectively). The $\mathrm{pH}$ was around neutral $(7.85 \pm 0.23,7.87 \pm 0.26$ and 7.69 \pm 0.33 at Sites 1, 2 and 3 respectively) throughout the study period at all study Sites. Both TDS and conductivity varied temporally and spatially at all locations although the conductivity and TDS values were within the range that drinking water should have. The total alkalinity was found to be low $(0.84 \pm 0.28,0.8 \pm 0.32$ and $0.87 \pm 0.26$ meq/L at Sites 1,2 and 3 respectively) resulting in high sensitivity of the reservoir even to a small change of $\mathrm{pH}$. Carbonate hardness varied both seasonally and spatially with a value of $48.6 \pm 6.9,45.6 \pm 8.1$ and $45.3 \pm 7.3 \mathrm{mg} / \mathrm{L}$ at Sites 1,2 and 3 respectively. With regard to conductivity, TDS, $\mathrm{pH}$ and hardness, although there were significant seasonal and spatial variations $(p<0.05)$, the values were within the acceptable range. However, the reservoir is characterized by unusual values of turbidity and transparency, which could be the major cause to the deterioration of the water quality of the reservoir.
\end{abstract}

Keywords: Water quality; Legedadi; Reservoir; Physico-chemical

\section{Introduction}

Fresh water bodies including reservoirs are finite resources essential for agriculture, industry, and drinking and household consumption. Without easily obtainable water of sufficient quantity and acceptable quality, sustainable socioeconomic development of a country is not achievable. Reservoirs are much more susceptible to environmental changes than natural water bodies and this in turn affects the aesthetics, the cost of drinking water treatment and the users [1].

Water quality of reservoirs is deteriorating due to both natural and anthropogenic effects. For example, in reservoirs situated in arid and semiarid areas, where surface water is naturally scarce, salinization is a severe problem [2]. In addition, in warm regions, high evaporation leads to high water loss and changes in physico-chemical characteristics of the water. Reservoirs evaporate more water than the natural surface water. Moreover, agriculture, industries and urban settlements adjacent to, or in the drainage basin of reservoirs further aggravate the deterioration of reservoirs' water quality and human health problems by releasing contaminants, through the discharge of waste waters in to these water bodies or their source water.

Legedadi Reservoir, which provides the largest proportion of drinking and house hold water supply for the city of Addis Ababa, has suffered during the last several decades, from various problems including smell, excessive consumption of copper sulphate and chlorine, color, and nuisance algal blooms. It is reported that the reservoir water has also failed to meet the world health organization's (WHO) requirements for potable water supply in turbidity and color from intermittent samplings [3]. In spite of these problems, there have been no long term studies conducted in the past two decades. There haven't been any studies conducted how the physicochemical parameters behave seasonally and spatially.

The objective of this study is, therefore, to investigate the major physico-chemical features in different seasons of the year, which have valuable implications to the water quality and known to be the basis for other water quality parameters in Legedadi Reservoir.

\section{Materials and Methods}

\section{Study site}

The reservoir investigated was Legedadi, situated about $30 \mathrm{~km}$ northeast of Addis Ababa, the capital of Ethiopia (Figure 1). Some geographic and morphometric features of Legedadi Reservoir and its catchment area are given in Table 1.

Legedadi is constructed for a single-purpose reservoir whose facilities include a dam and an impounded reservoir and a modern treatment plant. The latter is designed for a rated capacity of 150,000 $\mathrm{m}^{3} /$ day, i.e., about $80 \%$ of the daily water supply of the city. However, the catchment area analysis indicated that a safe yield of only 114,000 $\mathrm{m}^{3} /$ day which is an indication for a shortfall in the raw water supply of $36,000 \mathrm{~m}^{3} /$ day or annual storage depletion of $0.76 \%$ [3].

\section{Study design and sampling}

For this study, three sampling Sites in the reservoir were chosen: Sites 1, 2 and 3. Site 1, located close to the dam, is the deepest and site of algicide application; Site 2 is situated around the middle of the

${ }^{*}$ Corresponding author: Adane Sirage Ali, Department of Environmental Science Kotebe Metropolitan University, Addis Ababa, Ethiopia, Tel: 0116601277; E-mail: adnansirage@gmail.com

Received July 22, 2017; Accepted August 05, 2017; Published August 10, 2017

Citation: Ali AS, Tsega DK (2017) Seasonal and Spatial Dynamics of PhysicoChemical Characteristics as a Factor for Water Quality Deterioration in Legedadi Reservoir, Ethiopia. J Environ Anal Chem 4: 210. doi:10.41722380-2391.1000210

Copyright: @ 2017 Ali AS, et al. This is an open-access article distributed under the terms of the Creative Commons Attribution License, which permits unrestricted use, distribution, and reproduction in any medium, provided the original author and source are credited. 
reservoir, characterized by less disturbance and medium depth; and Site 3 is established at the rear side of the reservoir, shallowest, the site of intermittent river discharge and high human impacts.

From these Sites, water samples were taken every month and selected physico-chemical parameters were measured. The selected parameters were transparency, temperature, $\mathrm{pH}$, total alkalinity (TA), conductivity, hardness and total dissolved solids (TDS).

By using a motor boat, transparency, surface temperature, $\mathrm{pH}$ and conductivity were measured in situ, whilst for alkalinity, turbidity, hardness and total dissolved solids, integrated samples were taken using integrated water sampler for laboratory analysis.

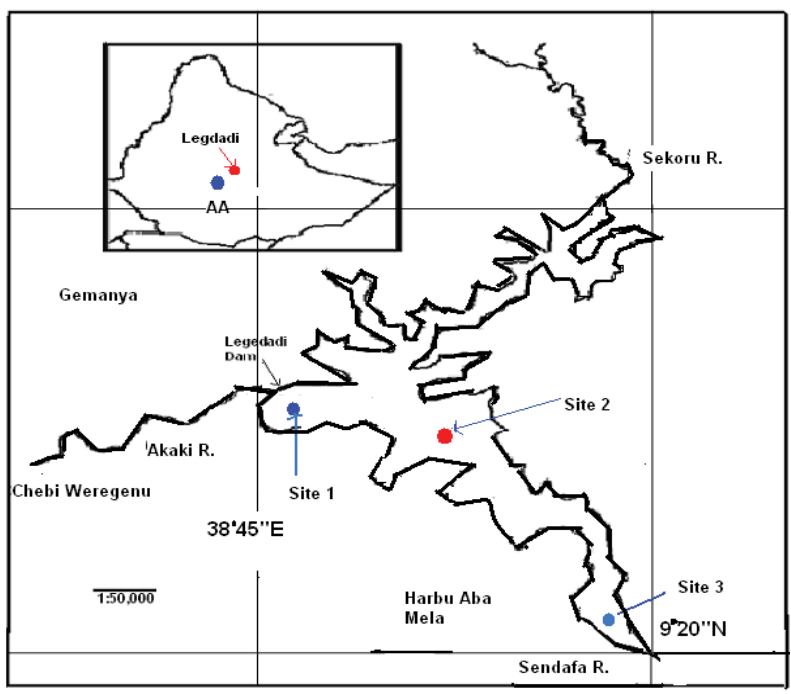

Figure 1: Map of Legedadi Reservoir with sampling sites indicated.

\begin{tabular}{|c|c|}
\hline Features & Measurement values \\
\hline Latitude & $9^{\circ} 20^{\prime} \mathrm{N}$ \\
\hline Longitude & $38^{\circ} 45^{\prime} \mathrm{E}$ \\
\hline Altitude $(\mathrm{m}$ a.s.l) & 2450 \\
\hline Area $\left[\right.$ ha $\left.\left(\mathrm{Km}^{2}\right)\right]$ & $452(200)$ \\
\hline Volume $\left(\mathrm{m}^{3}\right)$ & $50 \times 10^{3}$ \\
\hline Maximum depth $(\mathrm{m})$ & 34 \\
\hline Mean depth $(\mathrm{m})$ & 4 \\
\hline Catchments area, $\left[\mathrm{ha}\left(\mathrm{Km}^{2}\right)\right]$ & $20560(9097.35)$ \\
\hline Catchments altitude $(\mathrm{m}$ a.s.l) & $2460-3200$ \\
\hline
\end{tabular}

Table 1: Some morphometric and geographic features of Legedadi Reservoir and its catchments.

\section{Measurement of physico-chemical parameters}

Water level of the reservoir was taken from the installed elevation gauge at the dam side. Water transparency or Secchi depth was measured with a standard black and white Secchi disc of $20 \mathrm{~cm}$ in diameter. Turbidity was measured using direct reading Hack Kit (DR/4000 spectrophotometer).

$\mathrm{pH}$ of the surface water was measured in situ with a portable digital pH meter (Hanna 9024). Alkalinity due to carbonate and bicarbonate ions was determined within a few hours of sample collection by titration with $0.1 \mathrm{~N} \mathrm{HCl}$ to a $\mathrm{pH}$ of 4.5 using a mixed bromo cresol green methyl red indicator. Electrical conductivity was measured using portable digital conductivity meter integrated with temperature. Total hardness as calcium carbonate $\left(\mathrm{CaCO}_{3}\right)$ and total dissolved solids were analyzed using a Hach Kit (DR/4000 spectrophotometer) following the instructions of the manufacturer in AAWSA Central Laboratory.

\section{Results and Discussion}

\section{Changes in water level as a function of rainfall}

The reservoir's water level declined continuously throughout the dry seasons of the study period with a maximum decline of about 2 $\mathrm{m}$ during May, when the yearly hot weather prevailed and total yearly decline to be more than $7 \mathrm{~m}$ (Figure 2). However, the total annual increase in the same year was less than $2 \mathrm{~m}$ showing that the capacity of the reservoir is declining severely and the need to dredge the increasing siltation in the reservoir. The water level increases only during two heavy rainy months of the year (July and August). Such fluctuation of the water level will have negative attributes not only to the raw water quality but also it makes the treatment process very difficult and hence the potable water quality.

\section{Changes in surface water temperature}

Surface water temperature of the reservoir spatially varied slightly over the study period but temporally varied significantly $\left( \pm 2.4^{\circ} \mathrm{C}\right)$ with the maximum and minimum values recorded during the dry and rainy seasons respectively (Figure 3).

The surface water temperature of Legedadi Reservoir is lower than those reported for many lakes and reservoirs in Africa [4]. This may be partly due to the fact that Legedadi is located at higher altitude than the reported reservoirs.

\section{Seasonal and spatial changes in transparency}

Transparency of the reservoir water was found to be very low with mean values of $7.2 \mathrm{~cm}( \pm 0.6)$ at the dam site to a maximum $8.25 \mathrm{~cm}$ $( \pm 0.9)$ at the middle of the reservoir throughout the study period.

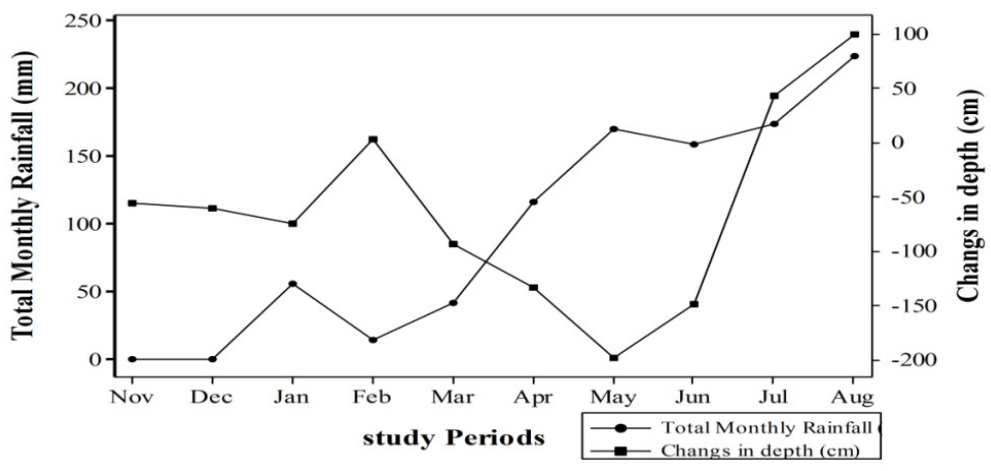

Figure 2: Total monthly rainfall and changes in the water level of Legedadi Reservoir. 
The maximum transparency was recorded during the dry seasons of the year at the middle of the reservoir. Relatively higher Secchi depth recorded during November, April and May may be due to the absence of run off input and bottom feeder fish at the middle and rear side of the reservoir. The year-round low transparency of the reservoir shows that the turbidity is not only due the influx of sediment during run off but also the resuspension of sediments by the water turbulence and bottom feeder fish in the reservoir. The high turbidity of the reservoir obviously makes the drinking water treatment very expensive and unless much attention is given, it will have no only serious potability problems including bad odor, taste as happened before but also other serious health consequences. It also increases chlorine consumption; otherwise the disinfection will be ineffective.
The variations between the three locations and over the study period were a maximum of 0.9 and $1.5 \mathrm{~cm}$ respectively (Figure 4).

\section{Seasonal and spatial dynamics in turbidity}

The mean turbidity values (in NTU) for Sites 1, 2 and 3 were 342.4 (range: 80-470), 305.1 (range: 63-442) and 348.8 (range: 51545) respectively, with maximum values recorded in November and December coinciding with dry months of the year (Figure 5). The turbidity level in Legedadi Reservoir has changed dramatically, with more than three-fold increase from previously recorded values. This may probably due to the influx of particulate materials from the catchment through runoff, the fairly high photosynthetic biomass and the resuspension of inorganic (silt and clay) and organic particles by

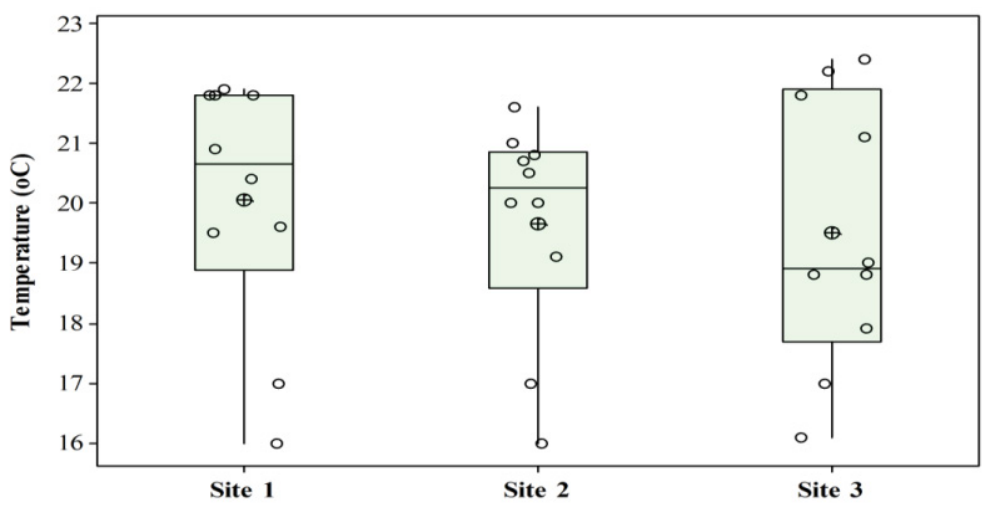

Figure 3: Seasonal and spatial changes of temperature in Legedadi Reservoir.

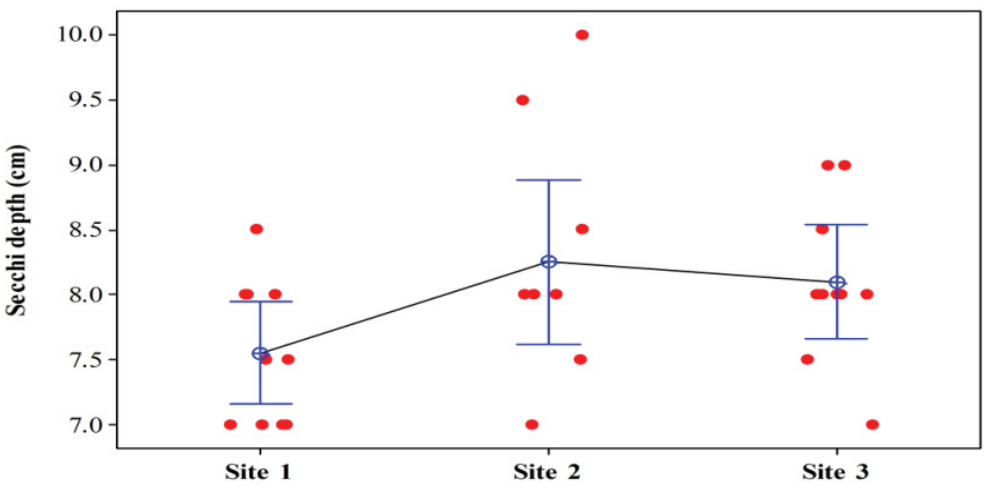

Figure 4: Seasonal and spatial variability of transparency in Legedadi Reservoir.

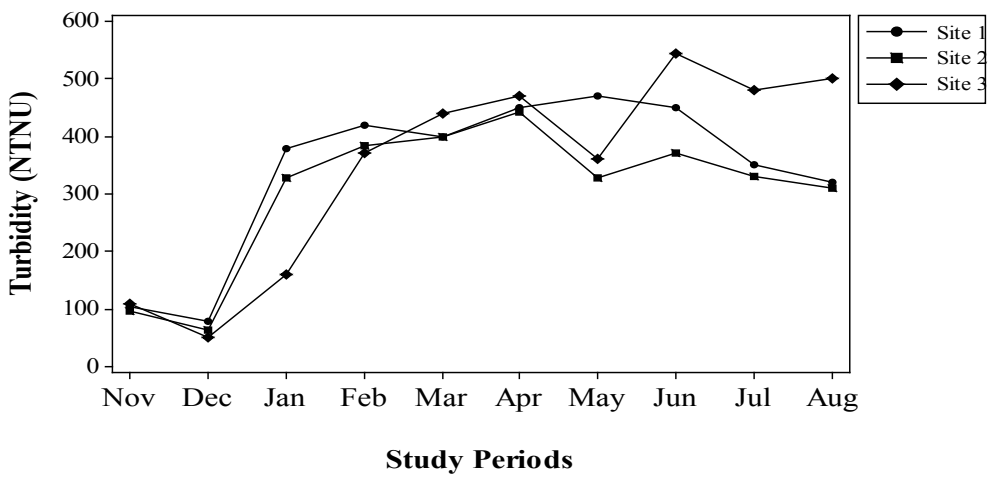

Figure 5: Temporal and spatial dynamics of turbidity in Legedadi Reservoir. 
the frequent wind-generated mixing. According to Addis Ababa water and sewerage authority, the treatment process is ineffective and very costly in terms of chemical consumption and this is clearly due to this high turbidity similar to many African reservoirs where high turbidity due to soil erosion caused drinking water treatment expensive and ineffective.

\section{Seasonal and spatial changes of $\mathrm{pH}$ and alkalinity}

The $\mathrm{pH}$ of the water was around neutral throughout the study period at all Sites with small variation temporally and spatially. The $\mathrm{pH}$ values of all sampling Sites were in the range of the highest desirable $\mathrm{pH}$ levels (6.5-9.5) [5] (Figure 6). The $\mathrm{pH}$ values of Legedadi are, however, closer to the upper boundary of the range of values within which most raw water lies (6.5-8.5).

Total alkalinity was found to be low with less spatial and temporal variations $(0.84 \pm 0.28,0.8 \pm 0.32$ and $0.87 \pm 0.26 \mathrm{meq} / \mathrm{L}$ at Sites 1,2 and 3 respectively (Figure 7). Compared with previous studies, the variation in alkalinity is found to be very low. Moreover, compared to the TA of most acceptable water supply sources, $0-8 \mathrm{meq} / \mathrm{L}[6]$ and to the expected total alkalinity values in nature, $0.4-40 \mathrm{meq} / \mathrm{L}$ [7], the total alkalinity of Legedadi Reservoir is low and close to the lower boundary values.

\section{Seasonal and spatial changes in TDS and conductivity}

The mean TDS values for Sites 1, 2, and 3 were 46.1 ( \pm 7.5), 45 ( \pm $9.4)$ and $45.7( \pm 6) \mathrm{mg} / \mathrm{L}$ respectively with less spatial and temporal variations in general (Figure 8 ). The correlation between conductivity and TDS for the reservoir was positive and very strong $(\mathrm{r}=0.8,0.9,0.9$ for Sites 1, 2 and 3 respectively) similar to many Ethiopian lakes [8].
In an earlier study conducted by Lehmusluoto [9] TDS values ranging from 62 to $77 \mathrm{mg} / \mathrm{L}$ were also observed.

For aesthetic reasons, a limit of $500 \mathrm{mgL}^{-1}$ has been established as part of secondary drinking water standards [10]. Water containing below $1000 \mathrm{mg} / \mathrm{L}$ TDS is usually acceptable while that with extremely low concentrations may be unacceptable to consumers owing to its flat insipid taste and corrosiveness to water supply systems [5]. The positive but weak correlation, between TDS and hardness ( $\mathrm{r}=0.35,0.37,0.29$ for Sites 1, 2 and 3 respectively), probably due to the presence of calcium and magnesium as important components of the TDS of Legedadi Reservoir.

The present conductivity values for Legedadi Reservoir are similar to those reported previously by AAWSA. The mean conductivity values were $94.6( \pm 16.73), 106.6( \pm 33.10)$ and $99.7( \pm 22.38) \mu \mathrm{S} / \mathrm{cm}$ at Sites 1,2 and 3 respectively (Figure 9). Both temporal and spatial variations in conductivity were low with minimum values recorded during November and December before the hottest months of the year come. The highest conductivity values in all the Sites during dry periods of the year and can be related to evaporative concentration of ions.

The lowest conductivity values were measured at times of maximum levels of water and vice versa indicating the apparent correlation between conductivity and water level, which is evident in Ethiopian lakes such as Lake Awassa [11], Lake Abijata [12].

\section{Conclusion}

All physico-chemical characteristics in Legedadi Reservoir showed both spatial and seasonal variations. Because of the consistently high

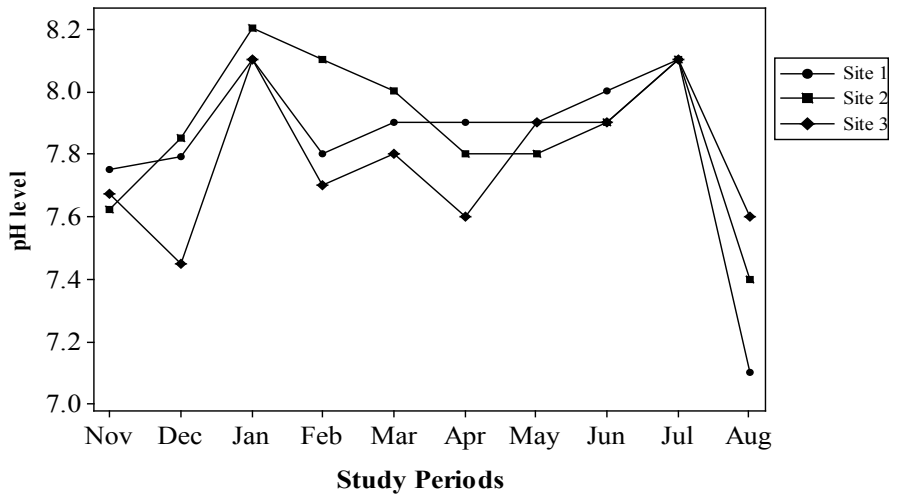

Figure 6: Seasonal and spatial variability of $\mathrm{pH}$ in Legedadi Reservoir.

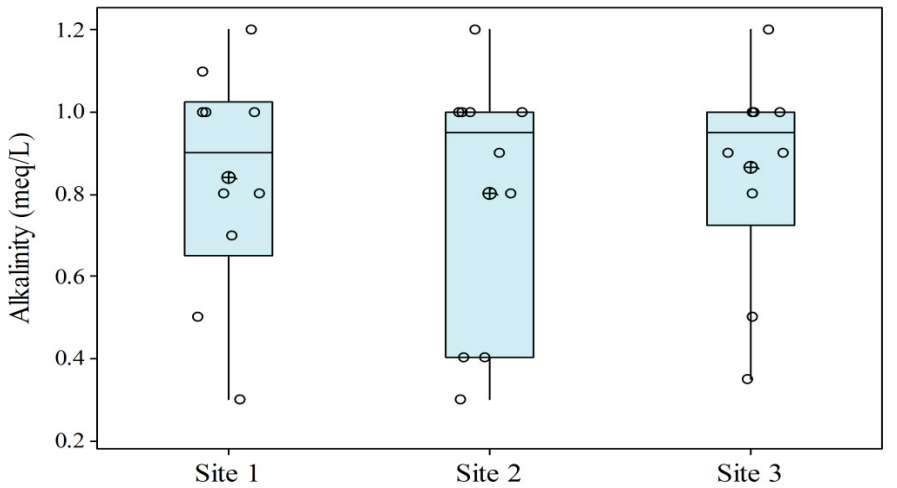

Figure 7: Seasonal and spatial variability of alkalinity in Legedadi Reservoir. 


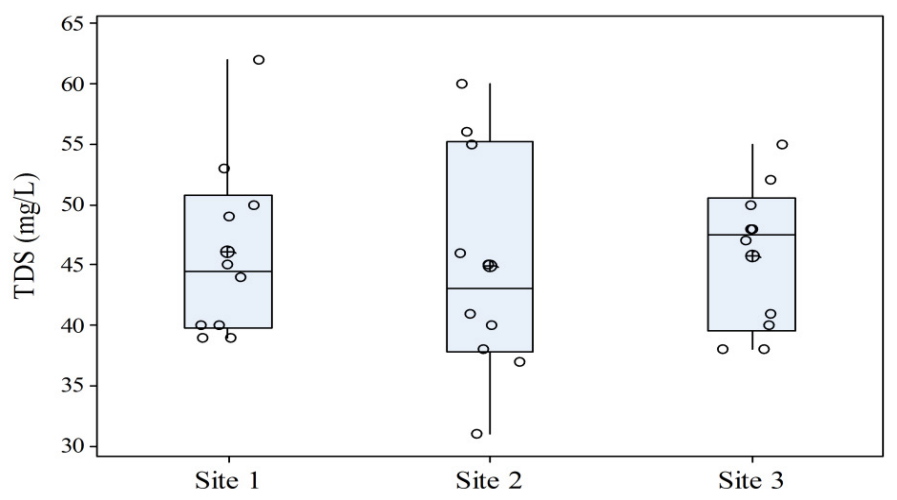

Figure 8: Seasonal and spatial variability of TDS in Legedadi Reservoir.

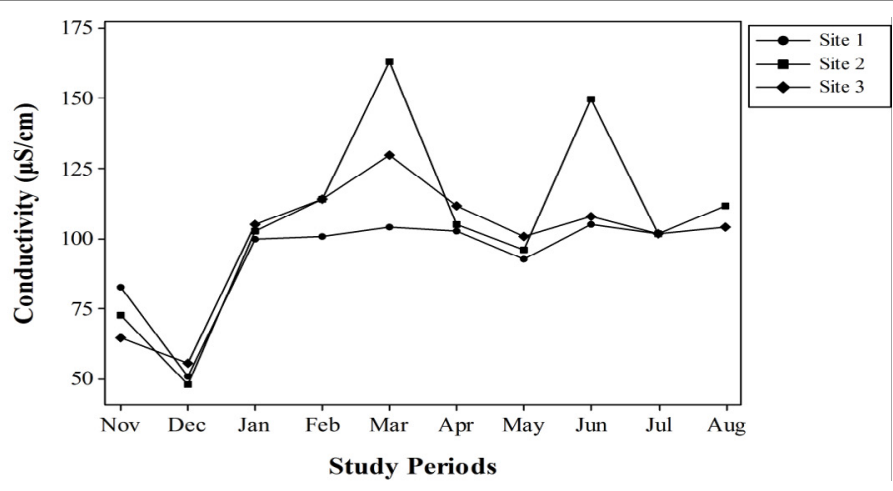

Figure 9: Seasonal and spatial variability of conductivity in Legedadi Reservoir.

levels of turbidity, transparency of the reservoir stayed unusually very low and this feature, in fact, selectively can create favorable conditions for nuisance algal blooms, which is common in most shallow reservoirs. Moreover, the year-round high turbidity level always makes the treatment process very expensive in terms of high chemical consumption and lowers the efficiency of the treatment plant. All the measured physico-chemical characteristics of the reservoir were changing in time series concomitantly with each other. Such dynamicity of chemical features needs special attention to many interrelated features such as watershed management issues, sediment dredging and increasing the efficiency of the plant.

\section{References}

1. Lampert W, Sommer U (1997) Limnoecology: The ecology of lakes and streams. Oxford University Press, Oxford, UK, p: 382.

2. Williams WD (2000) Dryland Lakes. Research Management. John Willey and Sons Ltd. 5: 207-212.

3. Arfi R (2003) The effects of climate and hydrology on the trophic status of Sélingué Reservoir, Mali, West Africa. Lakes and Reservoirs: Research and Management 8: 247-257.

4. Thomas S, Cecchi P, Corbin D, Lemoalle J (2000) The different primary productivity in a small tropical African Reservoir during a drought: Temporal changes and interaction. Freshwater Biol 45: 43-56.

5. WHO (1996) Guidelines for Drinking - Water Quality. WHO Geneva, Vol. 2.

6. Bailey D, Bilderback T (1998) Alkalinity control for irrigation water used in Nurseries and Greenhouses. Horticultural Information Leaflets, NC State University.

7. Lind OT (1979) Handbook of common methods in Limnology. The CV Mosby Company, p: 199.
8. Wood RB, Talling JF (1988) Chemical and algal relationships in salinity series of Ethiopian inland waters. Hydrobiologia 158: 29-67.

9. Lehmusluoto P (1999) Water for Addis Ababa, Capital of Ethiopia. Legedad Reservoir.

10. Environmental Quality Center, EQC (2003) Total Dissolved Solids (TDS) in drinking water quality. URL: http://www.water-research.net/totaldissolvedsolids. htm

11. Kassahun W, Amha B (1984) Species composition and seasonal abundance of zooplankton in two Ethiopian Rift Valley lakes - Lakes Abiata and Langano. Hydrobiologia 113: 129-136.

12. Elizabeth K, Amha B (1994) Species composition and phytoplankton biomass in at tropical African lake (Lake Awassa, Ethiopia). Hydrobiologia 288: 13-32. 